\title{
Uso de plantas medicinais no ensino de botânica para os anos finais do Ensino
}

\section{Fundamental}

\author{
Use of medicinal plants in teaching botany for the final years of Elementary School \\ Uso de plantas medicinales en la enseñanza de la botánica para los últimos años de la Escuela \\ Primaria
}

Recebido: 28/09/2021 | Revisado: 07/10/2021 | Aceito: 14/10/2021 | Publicado: 17/10/2021

\author{
Ana Kerly Oliveira de Brito \\ ORCID: https://orcid.org/0000-0002-3661-0359 \\ Universidade Estadual do Piauí, Brasil \\ E-mail: anakerlybrito@gmail.com \\ Ana Paula Apolinário da Silva \\ ORCID: https://orcid.org/0000-0001-8424-7323 \\ Universidade Estadual do Ceará, Brasil \\ E-mail: apaluap@hotmail.com \\ Rothchild Sousa de Morais Carvalho Filho \\ ORCID: https://orcid.org/0000-0002-7067-6159 \\ Universidade Estadual do Piauí, Brasil \\ E-mail: rothchildquimicahsb@gmail.com \\ Lidiane Assunção Araújo \\ ORCID: https://orcid.org/0000-0002-2324-2702 \\ Universidade Estadual do Piauí, Brasil \\ E-mail: lidy22aa@gmail.com \\ Patrícia Teixeira da Silva \\ ORCID: https://orcid.org/0000-0002-7457-5961 \\ Universidade Estadual do Piauí, Brasil \\ E-mail: patriciamelrylle@gmail.com \\ Antônia Flávia Silva Magalhães \\ ORCID: https://orcid.org/0000-0002-1485-1813 \\ Universidade Estadual do Piauí, Brasil \\ E-mail: flaviamagalhaes24@gmail.com \\ Maria Fabiana Araujo da Silva \\ ORCID: https://orcid.org/0000-0002-1859-9678 \\ Universidade Estadual do Piauí, Brasil \\ E-mail: fabysrt.04@gmail.com \\ Douglas Lima de Oliveira \\ ORCID: https://orcid.org/0000-0002-7066-1352 \\ Universidade Estadual do Piauí, Brasil \\ E-mail: douglaslima777@hotmail.com \\ Fernanda Meneses Amaral \\ ORCID: https://orcid.org/0000-0001-6439-6524 \\ Universidade Estadual do Piauí, Brasil \\ E-mail: fenetonanda@gmail.com \\ João Xavier da Silva Neto \\ ORCID: https://orcid.org/0000-0002-6981-2838 \\ Universidade Estadual do Ceará, Brasil \\ E-mail: xaviersn@live.com
}

\begin{abstract}
Resumo
O ensino de botânica é tratado como algo cansativo, difícil e, por vezes, pautado em uma abordagem que promove a memorização. Para ultrapassar tais barreiras viabilizando um aprendizado significativo, é necessário contextualizar o ensino a fim de fomentar uma aproximação entre o conhecimento científico e o cotidiano do aluno. Tendo isso em perspectiva, esse estudo objetivou realizar uma revisão de literatura com a finalidade de identificar práticas pedagógicas que fazem uso das plantas medicinais como estratégia para proporcionar a contextualização do ensino de botânica para os anos finais do Ensino Fundamental. Para tal, analisamos pesquisas publicadas de 1989 a 2019. Após aplicação de critérios de exclusão 7 publicações foram selecionadas, sendo todas artigos originais. Em um estudo minucioso identificamos características em comum nas abordagens metodológicas utilizadas, suscitando a criação de 5 categorias, sendo elas: aula prática, jogos didáticos, recursos visuais e audiovisuais, textos, visitação dirigida e apresentação. A análise dos trabalhos selecionados mostrou que há várias possibilidades para se abordar o ensino de botânica por meio
\end{abstract}


da temática das plantas medicinais, ocasionando uma melhor contextualização do ensino. Assim, concluímos que o uso das plantas medicinas é uma ferramenta eficaz para promoção da contextualização no ensino de botânica. Sobretudo, evidenciamos a necessidade do desenvolvimento de trabalhos que se utilizem dessa temática promovendo, além de uma abordagem diferenciada, uma ressignificação do aprender ampliando o diálogo entre escola, aluno e comunidade, contribuindo para que o educando atue como protagonista do seu próprio processo de ensino e aprendizagem.

Palavras-chave: Plantas medicinais; Ensino de botânica; Ensino fundamental.

\begin{abstract}
The teaching of botany is treated as something tiring, difficult and, at times, guided by an approach that promotes memorization. To overcome such barriers, enabling learning, it is necessary to contextualize teaching in order to foster a rapprochement between scientific knowledge and the student's daily life. With this in perspective, this study aimed to carry out a literature review with the identification of pedagogical practices that make use of medicinal plants as a strategy to provide a contextualization of the teaching of botany for the final years of Elementary School. To this end, we analyzed research published from 1989 to 2019. After applying the exclusion, 7 publications were selected, all of which were original articles. In a detailed study, we identified common characteristics in the methodological approaches used, prompting the creation of 5 categories, namely: practical classes, educational games, visual and audiovisual resources, texts, guided visitation and presentation. The analysis of the selected works showed that there are several possibilities to approach the teaching of botany through the theme of medicinal plants, bringing about a better contextualization of teaching. Thus, we conclude that the use of medicinal plants is an effective tool for promoting contextualization in the teaching of botany. Above all, we highlight the need to develop works that use this theme, promoting, in addition to a differentiated approach, a redefinition of learning, expanding the dialogue between school, student and community, contributing to the student to act as the protagonist of their own teaching process and learning. Keywords: Medicinal plants; Botany teaching; Elementary school.
\end{abstract}

\begin{abstract}
Resumen
La enseñanza de la botánica se trata como algo fatigoso, difícil y, en ocasiones, guiado por un enfoque que favorece la memorización. Para superar estas barreras, posibilitando el aprendizaje, es necesario contextualizar la enseñanza para propiciar un acercamiento entre el conocimiento científico y la vida cotidiana del alumno. Con esto en perspectiva, este estudio tuvo como objetivo realizar una revisión de la literatura con la identificación de prácticas pedagógicas que hacen uso de las plantas medicinales como estrategia para brindar una contextualización de la enseñanza de la botánica para los últimos años de la Escuela Primaria. Para ello, analizamos las investigaciones publicadas entre 1989 y 2019 . Tras aplicar la exclusión, se seleccionaron 7 publicaciones, todas ellas originales. En un estudio detallado, identificamos características comunes en los enfoques metodológicos utilizados, lo que motivó la creación de 5 categorías, a saber: clases prácticas, juegos educativos, recursos visuales y audiovisuales, textos, visita guiada y presentación. El análisis de los trabajos seleccionados mostró que existen varias posibilidades para abordar la enseñanza de la botánica a través del tema de las plantas medicinales, propiciando una mejor contextualización de la enseñanza. Así, concluimos que el uso de plantas medicinales es una herramienta eficaz para promover la contextualización en la enseñanza de la botánica. Sobre todo, destacamos la necesidad de desarrollar trabajos que utilicen esta temática, promoviendo, además de un enfoque diferenciado, una redefinición del aprendizaje, ampliando el diálogo entre escuela, alumno y comunidad, contribuyendo a que el alumno actúe como protagonista de su propio proceso de enseñanza y aprendizaje.
\end{abstract}

Palabras clave: Plantas medicinales; Enseñanza de la botánica; Enseñanza fundamental.

\title{
1. Introdução
}

Suscitar nos alunos o interesse pela botânica, é um desafio. Isso se agrava quando a proposta de ensino é baseada em uma metodologia convencional, limitada aos livros didáticos e aulas expositivas (Melo et al., 2012). Esse tipo de abordagem não favorece uma aprendizagem efetiva, uma vez que estimula os alunos à prática da memorização, fazendo com que os conteúdos vistos não passem de memória de curto prazo. Barros et al. (2013) ressaltam um outro aspecto que corrobora para o déficit na aprendizagem de botânica, a forma com que o conteúdo é apresentado no livro didático. Segundo os autores, "os livros didáticos de Ciências e Biologia trazem os conteúdos de botânica nos capítulos finais, contribuindo de forma involuntária para a desatenção desse tema".

Os alunos têm, geralmente, o primeiro contato com a botânica no $7^{\circ}$ ano do ensino fundamental e, mais tarde, no $2^{\circ}$ ano do ensino médio (Merhy \& Santos, 2017). É de extrema importância que os educandos consigam compreender conceitos botânicos básicos no Ensino Fundamental, para que possam entender conceitos mais complexos ao se depararem novamente 
com os conteúdos no Ensino Médio. No entanto, o que se observa na realidade das salas de aula e pelo relato de professores, é o desinteresse dos alunos no que diz respeito ao estudo das plantas.

Nesse sentido, Couto, Cavalcante e Lima (2018) relatam que os educandos não reconhecem a importância das plantas para o ser humano, sendo o interesse pela biologia vegetal ínfimo de modo que raramente as plantas são notadas e quando o são, não passam de um componente da paisagem ou objeto de decoração, perspectiva essa conhecida como "cegueira botânica". Essa constatação é reiterada por Medeiros e Crisostimo (2013) ao relatarem em seu trabalho que é significativo notar o desinteresse dos alunos do sétimo ano do Ensino Fundamental ante o conteúdo básico de botânica, principalmente em relação a classificação dos seres vivos.

Toda essa problemática em volta do ensino de botânica não está somente relacionada a falta de interesse dos alunos e o não reconhecimento da importância dos vegetais, mas também pelas dificuldades que os professores indicam acerca do tema (Faria, Jacabucci \& Oliveira, 2011). Para contornar toda essa situação, é necessário que educadores e alunos compreendam que para ensinar e aprender botânica muitas vezes é preciso apenas olhar para o lado de fora da sala de aula e observar práticas cotidianas, para notar que os vegetais estão em toda parte e são parte essencial da nossa vida. É necessário que se busque práticas que deem significado para o aprendizado, que contextualizem o ensino.

No âmbito dessa discussão, a utilização da temática das plantas medicinais torna-se uma alternativa para tentar superar as limitações e amenizar o quadro atual relacionado ao ensino de botânica, revelando-se uma importante ferramenta dado que permitem que os conhecimentos científicos e populares sejam trabalhados em conjunto, além de possibilitar uma abordagem interdisciplinar (Silva \& Santos, 2017). Ademais, o uso medicinal das plantas apresenta-se como uma estratégia que traz muitas possibilidades para o ensino de botânica, visto que proporciona a oportunidade de se tratar de conteúdos como, por exemplo, fisiologia vegetal (fotossíntese), morfologia (estrutura das plantas) e taxonomia (família botânica), além de trazer consigo múltiplos saberes, como: cultural, econômico, valor terapêutico e químico.

As plantas medicinais estão presentes em nossas vidas há milênios. Fazem parte de uma tradição popular que foi transmitida oralmente entre gerações e que, infelizmente, vem se perdendo com o passar do tempo. Quando utilizadas como recurso didático para fomentar a aproximação da cultura popular das famílias dos alunos ao conhecimento científico, são uma importante ferramenta para o ensino de botânica (Medeiros \& Crisostimo, 2013).

Frente a todas essas colocações, é pertinente destacar que estudos e pesquisas que procuram investigar estratégias e metodologias de ensino que têm como objetivo resgatar o conhecimento tradicional, em um processo de diálogo com o saber científico, são essenciais para a valorização da cultura popular e tradicional, (Kovalski \& Obara, 2013). Além disso, esses trabalhos trazem alternativas de metodologias mais eficientes no que tange um processo de ensino e aprendizagem, de fato, real e capaz de agregar conhecimento à vida dos estudantes.

Diante do exposto, esse artigo tem como objetivo realizar uma revisão bibliográfica com a finalidade de identificar práticas pedagógicas que fazem uso das plantas medicinais como estratégia para proporcionar a contextualização do ensino de botânica para os anos finais do Ensino Fundamental.

\subsection{Referencial teórico}

\subsubsection{Ensino de Ciências no Ensino Fundamental}

A ciência nasce do questionamento, e dele dar-se início o processo científico. $\mathrm{O}$ ato de questionar é inerente do ser humano, mas para que a ciência sobreviva e se dissemine, é necessário que suas descobertas sejam ensinadas. O ensino de Ciências é peça essencial para a produção do método científico e, da mesma forma que as ciências, a maneira de ensiná-las foi moldada com o passar dos anos (Silva, Ferreira \& Vieira, 2017). 
O ensino de Ciências Naturais é relativamente recente na escola fundamental. Tem sido empregado utilizando-se de diferentes propostas educacionais, que se sucedem ao longo das décadas. Entretanto, enquanto muitas práticas já incorporam novas estratégias didáticas, muitas ainda se baseiam na mera transmissão de informações, usando o livro didático e sua transcrição na lousa como únicos recursos (Brasil, 1998). Essa abordagem mecânica torna a disciplina cansativa e monótona sem despertar o interesse dos alunos evidenciando uma das grandes deficiências no processo de ensino e aprendizagem dos conteúdos de Ciências Naturais, a dificuldade dos discentes no que se refere a associação desses conteúdos com o seu cotidiano (Santos et al., 2015).

Assim, o processo de ensino e aprendizagem limita-se às perspectivas tradicionalistas nas quais prevalece o ensino voltado às ideias de neutralidade política e histórica da educação. Não obstante, ao analisar a própria história da ciência é visível a influência da historicidade com todas as variáveis sociais e políticas no que tange as descobertas científicas e avanços tecnológicos. "A distância entre ciências e sociedades é inexistente, sendo que a própria ciência é produto histórico das interações e ações humanas" (Silva, Ferreira \& Vieira, 2017).

Santos et al. (2015) afirmam que "o ensino de Ciências Naturais é de fundamental importância para formação de cidadãos críticos, com capacidade de interpretar o mundo a sua volta e a escola tem um papel importante na construção desses conhecimentos", pensamento esse que é ratificado pelos Parâmetros Curriculares Nacionais (PCN):

Considerando a obrigatoriedade do Ensino Fundamental no Brasil, não se pode pensar no ensino de Ciências Naturais como propedêutico ou preparatório, voltado apenas para o futuro distante. O estudante não é só cidadão do futuro, mas já é cidadão hoje, e, nesse sentido, conhecer Ciência é ampliar a sua possibilidade presente de participação social e desenvolvimento mental, para assim viabilizar sua capacidade plena de exercício da cidadania (Brasil, 1998).

O ensino de Ciências é uma das bases para a valorização do conhecimento científico, uma vez que engloba inúmeros conceitos importantes. Ao mesmo tempo, há um grande embate sobre como atuar no processo de ensino e aprendizagem de modo que lhe seja atribuída a devida importância a fim de que possa contribuir para a formação do aluno de forma científica, já que a escola tem esse importante papel.

Diante disso, "é imprescindível que haja uma valorização no ensino de ciências desde o Ensino Fundamental até o Ensino Médio" (Lima et al., 2019). Ainda mais quando se leva em consideração que "na educação contemporânea o ensino de Ciências Naturais é uma das áreas em que se pode reconstruir a relação ser humano/natureza em outros termos, contribuindo para o desenvolvimento de uma consciência social e planetária (Brasil, 1998).

Silva, Ferreira e Vieira (2017) ressaltam a importância do ensino contextualizado e instigador que, de acordo com os autores, "pode ser precursor do interesse de estudantes sobre o conhecimento científico e tal interesse pode perdurar na maturidade e, assim, mais jovens seguirem a carreira científica". Nessa perspectiva, metodologias e estratégias didáticas variadas, são extremamente importantes ao passo que possibilitam, aos professores, planejarem atividades que favoreçam a compreensão dos alunos em relação aos conteúdos curriculares, de modo a instigá-los a participarem das aulas (Kovalski \& Obara, 2013).

\subsubsection{Um panorama do ensino de botânica}

A relação do ser humano com as plantas remonta da época do gênero Homo há mais ou menos dois milhões de anos. Os registros em pinturas rupestres revelam que eles as usavam como remédio para curar enfermidades e as próprias pinturas eram realizadas com pigmentos de extratos vegetais (Amadeu \& Maciel, 2014). Atualmente, em decorrência das alterações ambientais e seus efeitos negativos, a preocupação com o meio ambiente é crescente. Essa problemática traz à tona a importância do conhecimento científico, em especial, o conhecimento da botânica para o controle dessas alterações e a prevenção de problemas futuros (Lazzari et al., 2017). 
O estudo das plantas e seu conhecimento está presente na vida do ser humano em várias áreas, embora muitos sequer se deem conta disso. A botânica está na alimentação, nos fármacos, em livros, mobília, cosméticos e até mesmo em nossa respiração (Lemos, Costa \& Rocha, 2015; Cunha, Rezende \& Saraiva, 2017). E tendo em vista a importância das plantas, a botânica é reconhecida como um dos conhecimentos conceituais da Biologia que deve ser ensinado no Ensino Fundamental e Médio das escolas, a fim de que o estudante possa desenvolver habilidades necessárias para a compreensão do papel das plantas na natureza (Brasil, 1998). Esta ciência também se mostra muito importante no passo que "contribui para a compreensão da linguagem da natureza que se manifesta ininterruptamente no cotidiano das pessoas" (Melo et al., 2012).

No entanto, atualmente o ensino de botânica é tido como "difícil" por alunos e professores da educação básica, pois se utiliza, na maioria das vezes, de listas de nomes científicos e palavras dissociadas da realidade do discente para definir conceitos, os quais nem sempre são compreendidos (Cruz, Joaquim \& Furlan, 2011). Lemos, Costa e Rocha (2015) ressaltam em seu trabalho que, "a falta de métodos eficazes para um bom repasse de conteúdo ou um mau planejamento de aula, com um mínimo de recursos, tende ao fracasso da aprendizagem dos alunos". Isso é reiterado pelos Parâmetros Curriculares Nacionais - PCNs para as Ciências Naturais ao especificarem que:

Se forem cobrados na aprendizagem numerosos nomes e definições, que para a maioria deles não têm o menor significado e apenas decoram para a prova, chegam a desenvolver repúdio a todo esse conhecimento e a desvalorizar suas reais curiosidades acerca dos ambientes e dos seres vivos. Esse tratamento raramente acrescenta conhecimentos sobre os papéis dos diferentes seres vivos nos ambientes em que vivem, ou convida os alunos a discutir por que e para que as classificações biológicas existem (Brasil, 1998).

É importante evidenciar que muitas são as dificuldades para se desenvolver atividades diferenciadas nas escolas públicas, principalmente em relação à falta de materiais. Entretanto, isso não é um empecilho, pois é possível tornar as aulas mais dinâmicas desenvolvendo-se atividades práticas que envolvam os alunos e os tornem protagonistas do processo educativo, isto, mesmo quando todo o contexto pareça demonstrar a impossibilidade de qualquer atividade não convencional (Menegazzo \& Stadler, 2012).

Ademais, abordagens diferenciadas permitem aos estudantes desenvolver novas habilidades relacionadas à conexão dos conhecimentos e sua aplicação nas mais diferentes situações do cotidiano. Sobretudo quando falamos do ensino de botânica, é muito importante promover o envolvimento dos saberes dos estudantes, fazendo uso de exemplos simples e do conhecimento dos mesmos para a explicação de processos relacionados às plantas, pois isso contribui para que os discentes possam se integrar de forma participativa nas explicações e se apropriar do conhecimento (Lazzari et al., 2017).

Na maior parte do Brasil a vegetação se apresenta de fácil acesso, o que dá margem para que o educador leve em consideração o uso de outros recursos pedagógicos para o ensino de botânica, com o intuito de despertar o interesse dos alunos e, principalmente, o gosto em aprender sobre as questões que cercam o reino vegetal (Cunha, Rezende \& Saraiva, 2017).

Dessa forma, os docentes devem utilizar-se de metodologias apropriadas, buscando desenvolver novas práticas que permitam aos alunos um melhor aprendizado, de forma a fazê-los encontrar suas próprias respostas e construir soluções para as situações-problemas presentes em seu cotidiano, posto que o ensino de Ciências deve servir para a formação da consciência crítica do educando, revertendo seus conhecimentos científicos em ações voltadas à melhoria da sua comunidade (Medeiros \& Crisostimo, 2013).

Nessa perspectiva, Kovalski e Obara (2013) destacam que:

No ensino de Ciências, é consenso a importância de se valorizar e resgatar os saberes que os alunos trazem de suas vivências e experiências exteriores à escola. Além disto, sabe-se que a escola e o professorado não devem ignorar a diversidade de culturas existentes na sociedade, porém precisam encontrar estratégias e metodologias para incluir e dialogar com os diferentes conhecimentos pertencentes aos estudantes. 
Ante o exposto, nota-se que as escolas, inclusive as escolas rurais, necessitam se voltar mais aos saberes do cotidiano, problematizar os conhecimentos tradicionais e populares que fazem parte da vida e da cultura dos seus alunos, para que estes possam construir uma leitura mais crítica sobre a realidade em que vivem (Kovalski \& Obara, 2013). O que também é enfatizado por Silva e Santos (2017) ao afirmarem que "a escola deve exercer o papel de valorização das experiências pessoais dos estudantes, despertando-lhes a atenção e a participação, ao permitir que consigam relacionar suas práticas cotidianas com os conceitos trabalhados em sala de aula".

\subsubsection{Plantas medicinais na contextualização do ensino}

A biodiversidade é responsável pela manutenção da vida na Terra, a interação entre os seres vivos e a oferta dos bens e serviços que são a base das sociedades humanas e suas economias. Sua manutenção é essencial para a saúde humana, com dependência direta da medicina natural e moderna (Medeiros \& Crisostimo, 2013). De acordo com Silva e Santos (2017), “a utilização dos vegetais para fins preventivos, curativos e para o tratamento de enfermidades é considerada uma das práticas mais antigas para o restabelecimento da saúde”. Em muitas comunidades, o uso das ervas é o principal recurso para o tratamento de muitas doenças, especialmente por trazer uma grande economia para as famílias. Todavia, é preocupante o uso descomedido que muitas pessoas fazem das plantas medicinais, sem se atentar ao risco, uma vez que muitas destas plantas apresentam toxicidade elevada e precisam ser utilizadas de forma adequada (Kovalski \& Obara, 2013).

Para a utilização correta das plantas medicinais é necessária realizar a identificação da doença ou dos sintomas apresentados, assim como a escolha apropriada da planta a ser utilizada e sua preparação correta. Ademais, um dos cuidados mais importantes é obter, com especialistas (botânicos) ou pessoas que têm tradição na utilização dessas plantas, como os raizeiros, a identificação adequada para reduzir riscos provenientes da utilização de plantas não indicadas para a doença (Silva, Santos \& Rabelo, 2010). É pertinente destacar que, quando consideramos as camadas economicamente menos favorecidas é evidenciado que estas recorrem, em primeiro lugar, aos conhecimentos da medicina popular, depois curandeiro e por último ao posto de saúde. Em contrapartida, ao analisarmos as classes mais favorecidas, nota-se que é feito justamente o caminho inverso (Medeiros \& Crisostimo, 2013).

Historicamente a produção de conhecimentos, de acordo com padrões e processos orientados por formas de organização sociais tradicionais, sempre foi uma importante fonte para o entendimento e aproximação com a natureza. O conhecimento tradicional é a forma mais antiga de produção de teorias, experiências, regras e conceitos. É a mais ancestral forma de produzir ciência (Ferreira et al., 2017). A escola, como ambiente de disseminação de conhecimento, valores e cultura, deve exercer o papel de valorização das experiências pessoais dos estudantes, despertando-lhes a atenção e a participação, ao permitir que os mesmos consigam relacionar suas práticas cotidianas com os conceitos trabalhados durante as aulas, contribuindo também para o resgate e preservação dos conhecimentos locais (Silva \& Santos, 2017).

Ao trabalhar a temática das plantas medicinais, professores podem contribuir para o ensino de Ciências e Biologia de modo que o conhecimento de cada discente pode ser levado em consideração, proporcionando a construção do conhecimento integrado entre ciência e saber popular. No entanto, é fundamental salientar para os estudantes a necessidade da verificação científica das propriedades medicinais das plantas para que o uso seja eficaz, levando-se em consideração os perigos, advertências e contraindicações de uso de determinadas plantas (Moitinho \& Marisco, 2015).

Segundo Medeiros e Crisostimo (2013), agregar o conhecimento popular dos alunos adquiridos através da convivência familiar ao conhecimento escolar, proporciona a valorização da cultura dos educandos possibilitando que adquiram informações a respeito das plantas como uso medicinal e nome científico, construindo uma ponte entre o conhecimento escolar e o mundo cotidiano dos alunos. Olguin et al. (2007) ressaltam que "é possível desenvolver alguns conceitos de Ciências Naturais a partir 
do tema plantas medicinais de forma integrada e interessante, resgatando a cultura popular e valorizando o ensino de Ciências como forma de compreender o mundo".

Na perspectiva do ensino de botânica, Medeiros e Crisostimo (2013) afirmam que "na escola as plantas medicinais oportunizam novos olhares sobre o ensino da botânica na disciplina de ciências". Desse modo, o "contato com exemplares de diferentes grupos de plantas proporciona aos alunos uma contextualização do conteúdo teórico visto em sala de aula e melhora da percepção de diversidade" (Silva \& Ghilardi-Lopes, 2014). Assim, destaca-se a relevância e necessidade da abordagem do tema plantas medicinais pelos professores de Ciências e Biologia e de uma discussão no meio acadêmico e nas políticas educacionais, visando contribuir para a melhoria do ensino de Ciências e Biologia, assim como seguir as orientações das diretrizes da Política Nacional de Plantas Medicinais e Fitoterápicos (Moitinho \& Marisco, 2015).

\section{Metodologia}

A referente pesquisa, de cunho qualitativo e quantitativo, trata-se de uma revisão sistemática da literatura. Nesse sentido, foi realizado um levantamento bibliográfico e análise das publicações relacionadas a temática do trabalho. Como base para a realização da pesquisa, foram seguidas as diretrizes estabelecidas por Moher et al. (2015) e adaptações de Moura et al. (2019). Dessa forma, foi produzido um levantamento bibliográfico sobre o tema: plantas medicinais no ensino de botânica para os anos finais do Ensino Fundamental.

Como primeiro passo para a seleção dos trabalhos utilizados nesta revisão, foi determinado que seriam utilizadas 4 bases de dados a serem consultadas (Google acadêmico, SciELO, Periódicos CAPES e Redalyc). Posteriormente, foi determinado que seriam efetuadas pesquisas englobando o período de 1989 a 2019 e que os termos de busca seriam "Plantas medicinais e ensino de botânica", "Ensino de botânica e Ensino Fundamental" e "Botânica e plantas medicinais".

Depois, utilizou-se de três critérios de exclusão a fim de diminuir a quantidade de trabalhos, bem como selecionar os mais relevantes para uma análise mais profunda. Em um primeiro momento, fez-se a exclusão de trabalhos repetidos em mais de um base de dados. Em seguida, foram excluídos os trabalhos que não eram artigos originais de pesquisa, livros e capítulos de livros. Por último, após a leitura dos trabalhos selecionados pelos critérios anteriores, foram excluídos da pesquisa todos os resultados que não se adequavam à proposta desta revisão.

\section{Resultados e Discussão}

Considerando-se todos os termos de pesquisa utilizados, obteve-se como resultado bruto um total 44.543 publicações. A distribuição geral de trabalhos por base de dados pode ser observada na Figura 1. Após o uso dos critérios de exclusão, foram obtidas um total de 7 pesquisas. A pequena quantidade final de pesquisas que se enquadravam no objetivo desta revisão e, portanto, foram mais profundamente analisadas (Tabela 1), pode ser explicada em parte, levando em consideração que muitos dos trabalhos detectados inicialmente eram resumos de congressos, simpósios, encontros universitários, ou trabalhos de conclusão de curso e não estavam publicados em formato de artigo de pesquisa original ou livros (ou capítulos de livros). 
Figura 1: Esquema geral para a seleção dos trabalhos analisados.

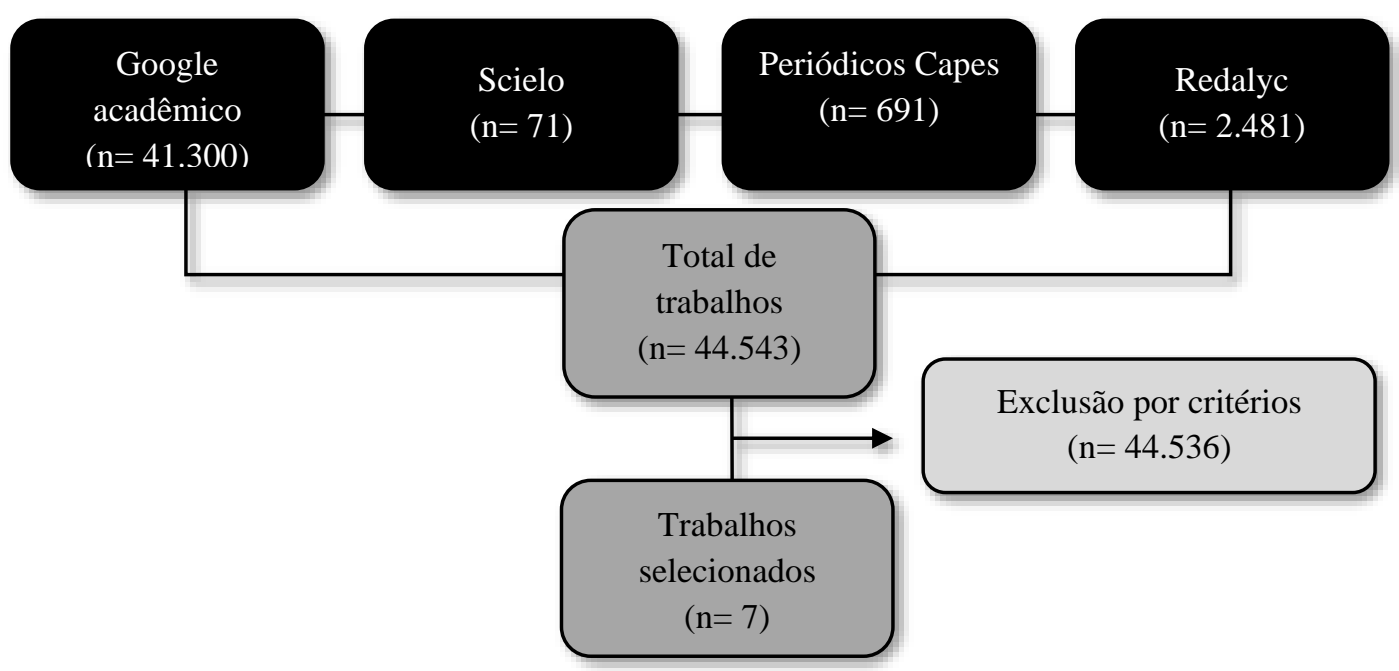

Fonte: Autores (2020).

Foram encontrados registros para todos os termos, sendo "Botânica e plantas medicinais" o que apresentou a maior ocorrência de resultados (16.236), ao passo que a combinação "Plantas medicinais e ensino de botânica" apresentou a menor quantidade de publicações (12.226), como pode ser observado no Gráfico 1. Dos trabalhos selecionados, 6 foram encontradas no banco de dados Google Acadêmico e 1 no Periódicos CAPES.

Gráfico 1: Números de resultados totais obtidos por cada combinação de palavras em cada um dos bancos de dados.

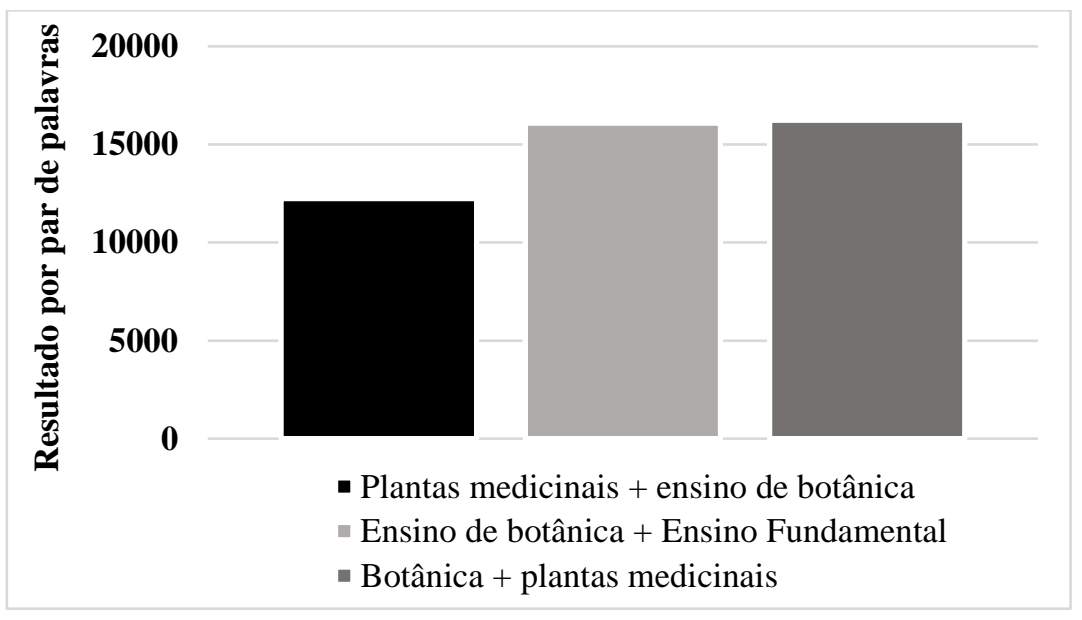

Fonte: Autores (2020).

Das 7 pesquisas selecionadas para a revisão, a maior ocorrência é registrada no ano de 2017 com 2 publicações. Com o agrupamento dos trabalhos selecionados, levando em consideração o ano da publicação, foi observado que o trabalho mais antigo datava do ano de 2007 e o mais recente, de 2019. Esses dados mostraram que a expansão das pesquisas relacionadas a temática abordada por esse trabalho, tomou mais força depois do ano de 2005. A distribuição anual de todas as publicações pode ser observada no Gráfico 2. 
Gráfico 2: Distribuição anual dos trabalhos revisados.

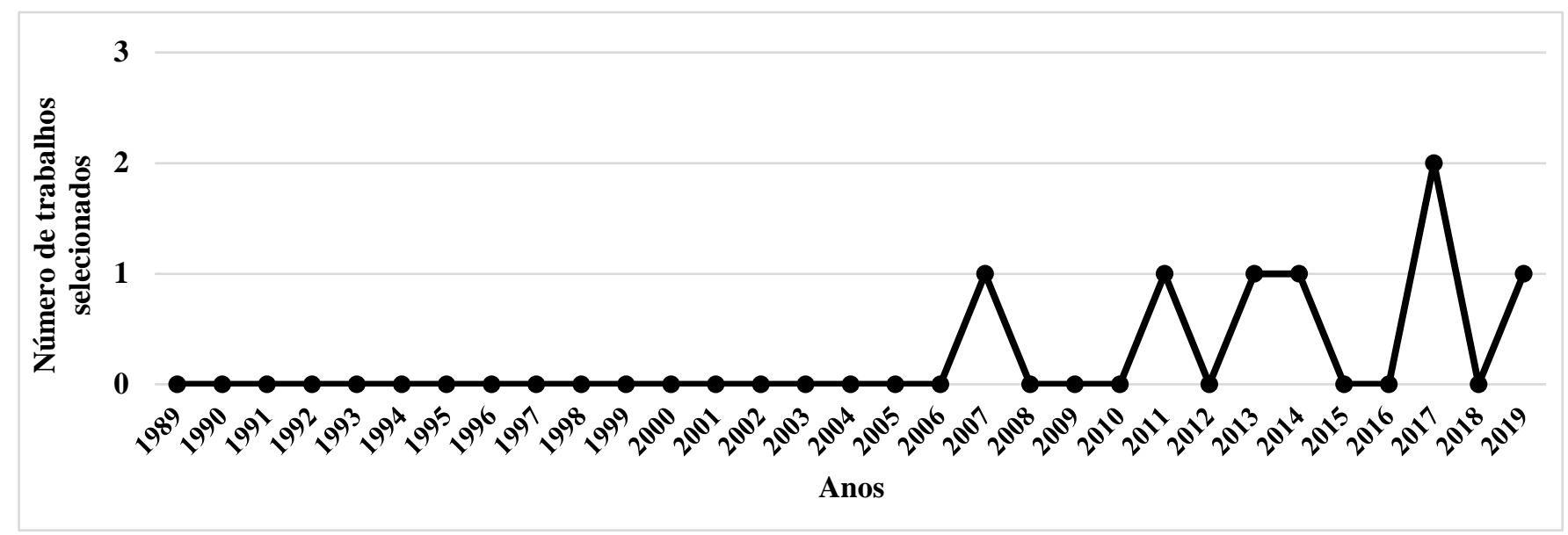

Fonte: Autores (2020).

Para auxiliar na discussão quanto a forma como as plantas medicinais foram empregadas para contextualização do ensino de botânica nas publicações analisadas, apresenta-se o Gráfico 3 que traz a quantidade de citações por estratégia/recurso metodológico adotado pelas publicações.

Gráfico 3: Número de citações por estratégia/recurso encontrados nas publicações analisadas.

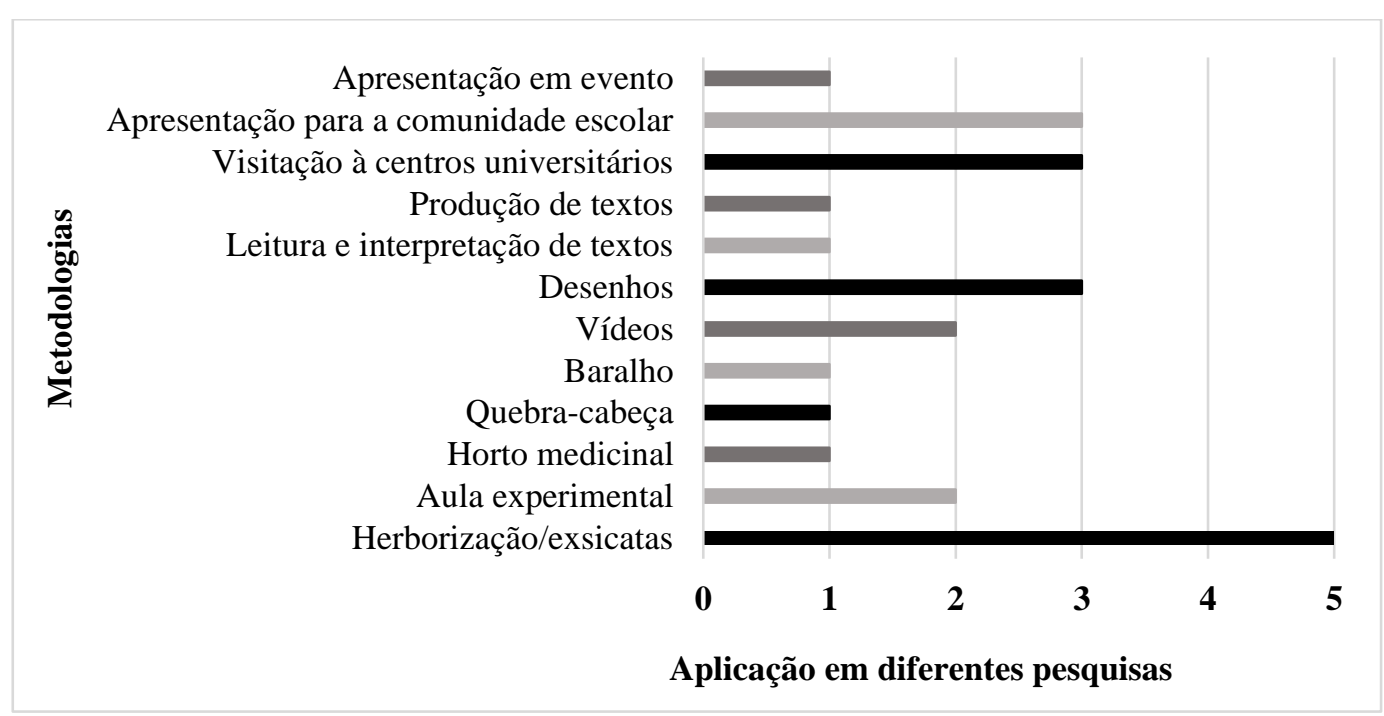

Fonte: Autores (2020).

A análise pormenores dos 7 artigos permitiu identificar características nas abordagens metodológicas utilizadas que suscitaram a criação de 5 categorias que surgiram com a finalidade de organizar as informações coletadas ressaltando nuances e similaridades entre os trabalhos, são elas: aula prática, jogos didáticos, recursos visuais e audiovisuais, texto, visitação dirigida e apresentação. O resultado final desse exercício de classificação, encontra-se expresso na Tabela 1. 
Tabela 1: Síntese das publicações por categoria.

\begin{tabular}{|c|c|c|c|}
\hline Categoria & Recurso/ estratégia & Série & Referência \\
\hline \multirow{4}{*}{ Aula prática } & \multirow{2}{*}{ Herborização/ exsicatas } & $7^{\circ}$ ano & $\begin{array}{l}\text { Silva e Santos (2017); Medeiros e Crisostimo (2013); Navarro et } \\
\text { al. (2007) }\end{array}$ \\
\hline & & $9^{\circ}$ ano & Ferreira; Batista e Pasa (2014); Silva e Castro (2019) \\
\hline & Horto medicinal & $7^{\mathrm{o}}$ ano & Navarro et al. (2007) \\
\hline & Experimento & $9^{\circ}$ ano & Ferreira; Batista e Pasa (2014); Silva e Castro (2019) \\
\hline \multirow{2}{*}{ Jogos didáticos } & Quebra-cabeça & $7^{\circ}$ ano & Medeiros e Crisostimo (2013) \\
\hline & Baralho & $7^{\mathrm{o}}$ ano & Ferreira et al. (2017) \\
\hline \multirow{5}{*}{$\begin{array}{l}\text { Recursos visuais } \\
\text { e audiovisuais }\end{array}$} & \multirow[b]{2}{*}{ Vídeo } & $7^{\circ}$ ano & Medeiros e Crisostimo (2013) \\
\hline & & $\begin{array}{l}7^{\circ} \text { ano } \\
8^{\circ} \text { ano }\end{array}$ & Cruz; Joaquim e Furlan (2011) \\
\hline & \multirow{3}{*}{ Desenhos } & $7^{\circ}$ ano & Ferreira et al. (2017) \\
\hline & & $9^{\circ}$ ano & Silva e Castro (2019) \\
\hline & & $\begin{array}{l}7^{\circ} \text { ano } \\
8^{\circ} \text { ano }\end{array}$ & Cruz; Joaquim e Furlan (2011) \\
\hline \multirow[b]{2}{*}{ Textos } & Leitura e interpretação & $7^{\circ}$ ano & Medeiros e Crisostimo (2013) \\
\hline & Produção & $\begin{array}{l}7^{\circ} \text { ano } \\
8^{\circ} \text { ano }\end{array}$ & Cruz; Joaquim e Furlan (2011) \\
\hline \multirow[t]{2}{*}{ Visitação dirigida } & \multirow{2}{*}{$\begin{array}{c}\text { Herbários e/ou } \\
\text { laboratórios em centros } \\
\text { universitários }\end{array}$} & $7^{\circ}$ ano & Medeiros e Crisostimo (2013); Navarro et al. (2007) \\
\hline & & $9^{\circ}$ ano & Silva e Castro (2019) \\
\hline \multirow{3}{*}{ Apresentação } & \multirow[b]{2}{*}{ Comunidade escolar } & $7^{\mathbf{o}}$ ano & Silva e Santos (2017); Medeiros e Crisostimo (2013) \\
\hline & & $9^{\circ}$ ano & Silva e Castro (2019) \\
\hline & Eventos & $7^{\circ}$ ano & Navarro et al. (2007) \\
\hline
\end{tabular}

Partindo da premissa de que a escola deve fazer uso do conhecimento prévio dos alunos para assim melhorar seu aprendizado, algo a ser destacado é referente a forma como os autores buscaram identificar os conhecimentos culturais e empíricos dos alunos a fim de trabalhar a proposta metodológica a partir deles. Dos 7 artigos: 2 usaram de um questionário (Medeiros \& Crisostimo, 2013; Silva \& Castro, 2019); 1 utilizou de um questionário e preenchimento de uma tabela com o nome de plantas medicinais populares (Ferreira et al., 2017); 1 realizou uma conversa informal (Silva \& Santos, 2017); 1 trabalho também utilizou-se de uma conversa informal, no entanto, esta ocorreu durante aula expositiva dialogada (Ferreira, Batista \& Pasa, 2014); e um último de uma roda de conversa na qual explicou-se oralmente a ação terapêutica de cada planta apresentada (Cruz, Joaquim \& Furlan, 2011). Apenas 1 trabalho não especificou se realizou essa sondagem inicial (Navarro et al., 2007).

$\mathrm{Na}$ análise das 7 publicações observou-se haver um consenso entre os autores no que se refere a necessidade de contextualização do conteúdo no ensino de botânica. Para tal fim, os autores citam que se pode utilizar do conhecimento que os alunos trazem consigo a fim de fomentar uma aproximação do saber científico com o que o aluno adquire pela sua vivência cotidiana, sendo essa uma forma de significar o aprendizado. Sobretudo, as publicações comprovam como a utilização da temática das plantas medicinais é uma importante ferramenta nesse sentido (Medeiros \& Crisostimo, 2013; Cruz, Joaquim \& Furlan, 2011; Ferreira et al., 2017; Silva \& Castro, 2019; Silva \& Santos, 2017; Navarro et al., 2007; Ferreira, Batista \& Pasa, 2014). 


\subsection{Breve apresentação das propostas metodológicas}

Na condução das atividades pedagógicas, elaboração e desenvolvimento, Medeiros e Crisostimo (2013) usaram diversos recursos metodológicos para ensinar botânica e favorecer a aquisição do conhecimento, foram eles: apresentação do conteúdo “Plantas Medicinais"' através de vídeos ocasionando um debate, estudo, leituras e interpretação de textos o qual teve o intuito de propiciar análise e reflexão aos educandos; visita ao Instituto Federal do Paraná - Campos de Palmas (IFPR) - para conhecer o acervo-Herbário Fitoterápico no laboratório de botânica; pesquisa sobre plantas medicinais da região; jogo interativo quebracabeça; construção de um herbário fitoterápico; finalizando com a apresentação dos trabalhos desenvolvidos para a comunidade escolar.

Cruz, Joaquim e Furlan (2011) produziram um estudo no qual verificaram o conhecimento de discentes sobre botânica e plantas medicinais. Os alunos tiveram contato manual com espécies de plantas medicinais (aprendendo sobre os odores, características singulares, riscos de manuseio e preparo inadequado). Depois, os educandos foram orientados a elaborar desenhos do corpo humano com a colagem de plantas, nos órgãos nos quais atuam terapeuticamente. Para se fazer uma análise dos conhecimentos anteriores e posteriores ao desenvolvimento da metodologia, solicitou-se que os discentes realizassem um registro escrito por meio de um texto.

Em estudo que visa resgatar os conhecimentos tradicionais de alunos do $7^{\circ}$ ano do ensino fundamental, fazendo um apanhado de conhecimentos botânicos e da medicina popular, Ferreira et al. (2017) realizaram um trabalho dividido em duas etapas que teve como base a produção de desenhos como forma de dinamizar o ensino. Na primeira etapa os alunos foram orientados a preencher uma tabela com o nome de plantas medicinais que conheciam e, em um segundo momento, foi solicitado que confeccionassem desenhos referentes às plantas medicinais citados na tabela, contendo identificação das estruturas das plantas. Na segunda etapa, com o intuito de fazer com que os alunos se identificassem como protagonistas do processo de ensino e aprendizagem, foram preparadas em slides, aulas relacionadas aos órgãos das plantas e o processo da fotossíntese, utilizandose dos desenhos produzidos pelos educandos. Além da aula, produziu-se também um jogo de baralho para que os discentes pudessem identificaram os órgãos das plantas e, além de verem seus desenhos como parte da aula, pudessem participar. Para averiguar se os alunos fixaram as informações, foi solicitado que produzissem novos desenhos de plantas medicinais, identificando suas estruturas com o nome que consta no conteúdo de ciência da série/ano estudado.

A publicação que tem como autores Silva e Castro (2019) traz uma proposta de ensino de botânica direcionada para alunos de $9^{\circ}$ ano de uma escola de comunidade quilombola, proposta essa que tem como finalidade gerar a identificação e aproximação do conhecimento quilombola do conhecimento escolar, posto que o conhecimento sobre as plantas medicinais se faz muito presente neste povo. Como estratégia metodológica, os autores: 1) Debateram com os alunos a respeito das partes que compõem os vegetais e, em seguida, orientaram os educandos a produzirem desenhos esquemáticos de pelo menos uma planta medicinal já utilizada por eles, discutindo com os demais qual planta estava sendo apresentada, o órgão utilizado e finalidade terapêutica; 2) realizaram atividade experimental, na qual fez-se uma análise micro e macroscópica de plantas medicinais; 3) utilizaram da técnica de herborização com plantas coletadas pelos próprios alunos na horta da escola, momento no qual foi abordado o histórico da utilização de plantas medicinais, nomes populares e nome científico que é necessário para identificação de uma determinada planta, além da importância do herbário; 4) Os estudantes confeccionaram pôsteres informativos sobre a classificação das plantas, sua utilização e contribuições medicinais, e realizou-se a apresentação para toda a comunidade escolar; 5) Concluindo a intervenção, foi realizada uma visita à UESB para conhecimento do Herbário e do Laboratório de Química de Produtos Naturais (LPN).

Silva e Santos (2017) relatam a experiência de aplicação de um projeto com alunos do $7^{\circ}$ ano de uma escola pública do estado do Rio de Janeiro. Na realização da proposta pedagógica, solicitou-se que os estudantes fizessem a coleta de plantas utilizadas por seus familiares e que subsequentemente realizassem o preenchimento de fichas de informações sobre a coleta e 
uso das plantas correspondente a cada planta coletada. Em um momento seguinte, aplicou-se a técnica de herborização, seguida da produção de exsicatas para a criação de um álbum herbário na escola. Realizou-se também uma apresentação dos trabalhos em uma Feira Multidisciplinar que ocorreu na própria escola onde o trabalho foi desenvolvido, momento no qual os alunos puderam expor o álbum herbário já finalizado, juntamente com um banner contendo, de forma resumida, as informações da atividade de coleta das plantas desenvolvida por eles.

No intuito de dar mais significado para o ensino de botânica na Educação de Jovens e Adultos (EJA), Ferreira, Batista e Pasa (2014) aplicaram uma proposta que tem como base uma abordagem voltada para o resgate dos conhecimentos sobre o uso medicinal das plantas e a atividade experimental. Para tal, foram realizadas aulas experimentais no laboratório da escola no qual os discentes puderam contar com preparados botânicos em álcool, além de participar da aula ajudando na montagem de lâminas histológicas e, a partir do ensino do funcionamento do microscópio, estes puderam visualizar células, glândulas (com ingrediente ativo) e tricomas em cortes paradérmicos da folha de boldo. Também houve a construção de exsicatas.

Navarro et al. (2007) realizaram um projeto fruto de uma pareceria entre a Universidade Estadual de Ponta Grossa (UEPG) e uma escola da rede estadual de ensino, no qual participaram 4 alunos da $6^{\text {a }}$ série (atual $7^{\circ}$ ano) do ensino fundamental, segundo os autores, "motivados pela experimentação do uso das plantas medicinais como ferramenta de tradução de conteúdos de ciência para situações do cotidiano". O primeiro passo do projeto foi a reativação e adequação do horto medicinal da escola. As espécies medicinais cultivadas forma selecionadas de modo a subsidiar o projeto. Os alunos participaram da coleta e dessecação dos órgãos dos espécimes em estudo. Em seguida os educandos realizaram uma visitação aos laboratórios de pesquisa da UEPG e acompanharam o processo de extração de óleos essências e a produção de extratos vegetais. Os estudantes participaram de eventos, em especial do I Educação com ciência (2005) apresentando suas atividades ao público, também orientando as pessoas sobre o preparo de medicamentos caseiros. Além da participação oral, de pôsteres e de anais, foram distribuídos 4000 pacotes artesanais de sachês de cravo-da-índia e capim-limão, elaborados pelos discentes, e mudas de arruda e alecrim.

\subsection{Análise das propostas metodológicas}

Pelo breve resumo de cada trabalho apresentado na seção anterior e pela síntese presente na tabela 1, é possível constatar que existem diversas formas de se trabalhar com a temática das plantas medicinais dentro do ensino de botânica. Pode-se observar também que todos os artigos buscaram utilizar mais de uma estratégia metodológica.

A herborização/confecção de exsicatas foi a prática mais adotada (Medeiros \& Crisostimo, 2013; Silva \& Santos, 2017; Ferreira, Batista \& Pasa, 2014; Silva \& Castro, 2019; Navarro et al., 2007), seguida da produção de desenhos com 3 citações (Ferreira et al., 2017; Silva \& Castro, 2019; Cruz, Joaquim \& Furlan, 2011). A atividade experimental teve 2 citações (Ferreira, Batista \& Pasa, 2014; Silva \& Castro, 2019). Tem-se também que 2 trabalhos usaram vídeos (Medeiros \& Crisostimo, 2013; Cruz, Joaquim \& Furlan, 2011); 1 publicações fez uso de textos para leitura e interpretação (Medeiros \& Crisistimo, 2013) e 1 utilizou-se de produção textual (Cruz, Joaquim \& Furlan, 2011). Apenas um dos trabalhos realizou a implementação de horto medicinal na escola (Navarro et al., 2007). Para inserir os alunos no contexto universitário e aproximá-los ainda mais do conhecimento científico, 3 trabalhos realizaram visitação dirigida a centros universitários com a finalidade de mostrar para os alunos os herbários (Medeiros \& Crisostimo, 2013; Silva \& Castro, 2019) e laboratório de extração de óleo essencial (Navarro et al., 2007). Em 3 trabalhos, os alunos fizeram a apresentação para a comunidade escolar a fim de compartilhar do conhecimento adquirido com a aplicação da abordagem metodológica (Silva \& Santos, 2017; Medeiros \& Crisostimo, 2013; Silva \& Castro, 2019) e em 1 os alunos participaram de eventos científicos fazendo apresentação oral e em pôster (Navarro et al., 2007).

Medeiros e Crisostimo (2013) assinam a publicação que mais diferenciou a sua metodologia acrescentando diversas atividades (pesquisa, leitura e interpretação de textos, análises de imagens e vídeos, jogo didático visitação a um centro 
universitário, construção de herbário fitoterápico e apresentação dos trabalhos para a comunidade escolar). De acordo com as autoras, a realização das estratégias propostas em seu trabalho, proporcionou aos educandos a construção do saber científico, além da análise e reflexão do seu comportamento em relação aos cuidados com o uso inadequado das plantas medicinais. Ademais, as ações desenvolvidas também oportunizaram a conscientização sobre a importância do tema abordado e do ensino da botânica, valorizando a disciplina de Ciências como uma forma de compreender o mundo em que vivemos. Além disso, as atividades diferenciadas propiciaram aos alunos demonstrar aptidões cognitivas, promovendo assim, aprendizagem significativa.

Silva e Castro (2019) mencionam que a realização de aula experimental com a utilização do estereomicroscópio para visualização das plantas proporcionou a observação ampliada, aguçando a curiosidade dos estudantes dando-lhes a oportunidade de visualizar estruturas como os tricomas presentes nas folhas de espécies do gênero Lamiaceae. Ainda, expressam que "a presença destes equipamentos, instigaram os estudantes que relataram a necessidade destes na escola. Desta maneira, estes instrumentos didáticos podem facilitar o processo de ensino-aprendizagem, quando disponíveis".

Sobre seu estudo, Ferreira, Batista e Pasa (2014) destacam que com as atividades desenvolvidas, notou-se que os alunos mostraram-se mais interessados pela botânica, uma vez que as práticas experimentais deram uma contribuição significativa para o aprendizado, despertando o olhar científico do aluno, bem como, ajudou os professores da instituição escolar a perceberem a importância de se utilizar de metodologias diferenciadas para promover uma aprendizagem mais efetiva dos conteúdos abordados em sala de aula. Desse modo, "a utilização de plantas medicinais como instrumento didático para facilitar o ensino de botânica tornou-se, então, uma ferramenta muito eficaz na aprendizagem".

A respeito da utilização da técnica de herborização/confecção de exsicatas Medeiros e Crisostimo (2013), Silva e Santos (2017) e Ferreira, Batista e Pasa (2014) puderam constar que tal atividade proporcionou uma aproximação dos alunos ao conhecimento científico, oportunizando o desenvolvimento de habilidades como observação, comparação e organização, além de despertar a curiosidade dos educandos, fomentando assim uma aprendizagem mais significativa.

Com relação à visitação a centros universitários, Medeiros e Crisostimo (2013) e Silva e Castro (2019), perceberam que além de possibilitar uma aproximação e interesse pelo saber científico, essa atividade contribui sobremaneira para a interação dos educandos com os conteúdos teóricos desenvolvidos em sala de aula, entendendo como o conhecimento popular está entrelaçado ao conhecimento científico, bem como perceber a relevância de ambos para a história da ciência.

Em relação aos jogos didáticos, os autores citam que estes propiciaram a interação, socialização e estimularam os alunos gerando expectativa, emoção e concentração, mostrando que o lúdico é uma boa ferramenta para ajudar a fixar os conteúdos trabalhados em sala de aula, nesse caso em especial, sobre as plantas medicinais (Ferreira et al., 2017; Medeiros \& Crisostimo, 2013). No que se refere a utilização de vídeos, Medeiros e Crisostimo (2013), salientam que "vídeo é uma fonte muita valiosa e uso adequado faz parte das novas tecnologias, pois são capazes de agregar elementos importantes dos conteúdos no processo ensino-aprendizagem, podendo atingir os educandos de várias maneiras".

Quanto a apresentação oral dos trabalhos desenvolvidos durante a aplicação da proposta metodológica, os autores afirmam que permite atrelar o conhecimento científico ao saber popular, além de estimular os educandos a desenvolverem a oralidade e compartilhar informações importantes não só para eles, como para a comunidade como um todo (Silva \& Castro, 2019; Medeiros \& Crisostimo, 2013).

Ferreira et al. (2017), relatam sobre a utilização de desenhos de forma a valorizar a produção do aluno afirmando que "seus desenhos utilizados nos slides fizeram com que eles se mantivessem conectados ao professor e ao tema proposto. Fato este que podemos afirmar contribuiu para uma melhor compreensão dos conceitos discutidos durante as aulas".

Com relação ao estudo desenvolvido por Cruz, Joaquim e Furlan (2011), é importante destacar, além das conclusões sobre a aplicação da metodologia com os alunos, suas constatações quanto aos professores, que também foram alvo de pesquisa. Ao final da aplicação da proposta metodológica os autores verificaram que os alunos não tinham conhecimentos efetivos sobre 
a diversidade de plantas medicinais presentes na flora brasileira. No entanto, por meio da análise dos textos produzidos, notaram que o projeto trouxe para os alunos uma nova ferramenta para estimular a valorização da natureza, bem como a obtenção de novas informações, além das já adquiridas pelo conhecimento popular. Inclusive, pela fala dos professores, foi possível perceber a contribuição do estudo, mais especificamente sobre o ensino e aprendizagem das plantas medicinais no ensino fundamental, de modo que este proporcionou a valorização dos conhecimentos prévios dos alunos, pois esse tema é em si "uma proposta rica em possibilidades para serem trabalhas até com os professores de outras disciplinas e o estudo também ressalta a importância das plantas medicinais e alerta sobre a sua utilização".

\section{Considerações Finais}

A análise sistemática das publicações selecionadas na pesquisa que deu origem a essa revisão, mostrou que há várias possibilidades para se trabalhar o ensino de botânica por meio da temática das plantas medicinais, foram citados pelos autores: a técnica de herborização (sendo a mais citada); atividade experimental; implementação de horto medicinal; produção, leitura e interpretação de textos; analise de vídeos; aplicação de jogos didáticos; visitação à centros universitários; e, como forma de compartilhar os conhecimentos adquiridos, a apresentação oral das produções desenvolvidas.

Conclui-se, portanto, que o estudo das plantas medicinais como ferramenta pedagógica no ensino de botânica para os anos finais do ensino fundamental, contribui sobremaneira para o processo de ensino e aprendizagem, uma vez que propicia um grande conhecimento do mundo vegetal e a inserção de um rico conteúdo científico, além de proporcionar o resgate cultural de potencialidades terapêuticas das plantas e uma aproximação entre o saber popular e a ciência. Sobretudo, evidencia-se a necessidade do desenvolvimento de trabalhos que se utilizem dessa temática promovendo, além de uma abordagem diferenciada, uma ressignificação do aprender, ampliando o diálogo entre escola, aluno e comunidade.

\section{Referências}

Barros, M. F., Farias, G. B., Silveira, E. S. M., Santiago, A. C. P. (2013). Análise da abordagem sobre pteridófitas em livros didáticos de ciências do Ensino Fundamental. Acta Scientiae, Canoas. 15 (2), 321-337.

Brasil. Secretaria de Educação Fundamental. (1998). Parâmetros curriculares nacionais: Ciências Naturais. MEC /SEF, 139.

Couto, C. A., Cavalcante, F. S. \& Lima, R. A. (2018). Concepções sobre o ensino aa fotossíntese com alunos do ensino fundamental no município de Porto Velho-RO. C\&D-Revista Eletrônica da FAINOR. 11 (3), 643-652.

Cunha, N. C., Rezende, J. L. P. \& Saraiva, I. S. (2017). Análise do conteúdo de botânica nos livros didáticos do ensino fundamental. Argumentos Pró-Educação. $2(6), 493-513$.

Cruz, L. P., Joaquim, W. M. \& Furlan, M. R. (2011). O estudo de plantas medicinais no ensino fundamental: uma possibilidade para o ensino da botânica. Thesis, 15,15 .

Faria, R. L., Jacobucci, D. F. C., Oliveira R. C. (2011). Possibilidades de ensino de botânica em um espaço não-formal de educação na percepção de professoras de ciências. Rev. Ensaio. 13 (1), 87-104.

Ferreira, A. L. S., Batista, C. A. S. \& Pasa, M. C. (2014). Botânica experimental no Ensino De Jovens E Adultos (EJA): Uma abordagem etnobotânica. FLOVET. $1(6)$.

Ferreira, G., Campos, M. G. P. A., Pereira, B. L. \& Santos, G. B. (2017). Etnobotânica e o ensino de botânica do ensino fundamental: possibilidades metodológicas para uma prática contextualizada. FLOVET. 1 (9).

Kovalski, M. L. \& Obara, A. T. (2013). O Estudo da Etnobotânica das Plantas Medicinais na escola. Ciência \& Educação (Bauru). 19 (4), $911-927$.

Lazzari, G. Z., Gonzatti, F., Scopel, J. M. \& Scur, L. (2017). Trilha ecológica: um recurso pedagógico no ensino da Botânica. Scientia cum Industria. 5 (3), 161167.

Lemos, J. R., Costa, R. M. V. \& Rocha, L. D. A. (2015). Botânica: Dificuldades de aprendizado dos alunos de $7^{\circ}$ ano em escolas da rede municipal de Santa Quitéria, Maranhão. Acta Tecnológica. 10 (1), 73-79.

Lima, R. A., Pinto, M. N., Mendoza, A. Y. G., Silva, D. R., Nascimento, F. A., Rodrigues, J. J. P., Almeida, K. P. C., Vieira, R. L. \& Assis, S. N. S. (2019). A importância das plantas medicinais para a construção do conhecimento em botânica em uma escola pública no município de Benjamin Constant - Amazonas (Brasil). Revista Ensino de Ciências e Humanidades. 5 (2), 478-492. 
Research, Society and Development, v. 10, n. 13, e408101321196, 2021

(CC BY 4.0) | ISSN 2525-3409 | DOI: http://dx.doi.org/10.33448/rsd-v10i13.21196

Medeiros, E. T. O. \& Crisostimo, A. L. (2013). A importância da aprendizagem das plantas medicinais no ensino da botânica. Cadernos PDE. Curitiba: SEED/PR., 1.

Melo, E. A., Abreu, F. F., Andrade, A. B. \& Araujo, M. I. O. (2012). A aprendizagem de botânica no ensino fundamental: Dificuldades e desafios. Scientia Plena. 8 (10)

Menegazzo, R. C. S.; Stadler, R. C. L. (2012). Estratégia para despertar o interesse dos educandos para a botânica: construção de um herbário no ensino fundamental. Revista Ciências \& Ideias. 4 (1).

Merhy, T.S. M. \& Santos, M. G. (2017). A Etnobotânica na escola: interagindo saberes no ensino fundamental. Revista Práxis. 9 (17).

Moher, D., Shamseer, L., Clarke, M., Ghersi, D., Liberati, A., Petticrew, M., Shekelle, P., Stewart, L. A. \& PRISMA-P Group (2015). Preferred reporting items for systematic review and meta-analysis protocols (PRISMA-P) 2015 statement. Systematic Reviews. 4, 1-9.

Moitinho, L. \& Marisco, G. (2015). A importância da abordagem de plantas medicinais na escola. Scientia Amazonia. 4 (5).

Moura, L. F. W. M. G., Silva Neto, J. X., Lopes, T. D. P., Benjamin, S. R., Brito, F. C., Magalhães, F. E. A., Florean, E. O. P. T., Sousa, D. O. B. \& Guedes, M. I. F. (2019). Ethnobotanic, phytochemical uses and ethnopharmacological profile of genus Cnidoscolus spp. (Euphorbiaceae): A comprehensive overview. Biomedicine \& Pharmacotherapy. 109, 1670-1679.

Navarro, D. F., Marcondes, N. S. P., Volpato, A. M. M., Farago. P. V., Serenato, T., Moreira, E. E. M., Costa, R. G. \& Machado, W. M. (2007). Utilização de plantas medicinais e aromaterapia como ferramenta no ensino fundamental das ciências. Revista Conexão UEPG. 3 (1), 62-67.

Santos, C. J. S., Brasileiro, S. G. S., Maciel, C. M. L. A., \& Souza, R. D. (2015). Ensino de Ciências: Novas abordagens metodológicas para o ensino fundamental. Revista Monografias Ambientais. 14, 217-227

Silva, W. J. \& Castro, M. M. (2019). Conhecimento quilombola e plantas medicinais: recursos didáticos para o ensino de ciências. Revista ODEERE. 4 (8).

Silva, A. F., Ferreira, J. H. \& Vieira, C. A. (2017). O ensino de ciências no Ensino fundamental e médio: reflexões e perspectivas sobre a educação transformadora. Revista Exitus.. 7 (2), 283-304.

Silva, J. \& Ghilardi-Lopes, N. (2014). Botânica no Ensino Fundamental: diagnósticos de dificuldades no ensino e da percepção e representação da biodiversidade vegetal por estudantes de escolas da região metropolitana de São Paulo. Revista Electrónica de Enseñanza de las Ciencias. 13, 115-136.

Silva, D. F.; Santos, M. G. (2017). Plantas medicinais, conhecimento local e ensino de botânica: uma experiência no ensino fundamental. Revista Ciências \& Ideias. 8 (2).

Silva, A. F., Santos, A. P. \& Rabelo, M. F. R. (2010). Identificação botânica das plantas medicinais. Informe Agropecuário. 31 (255), 77- xx. 